\title{
Robotic transcatheter aortic valve replacement with magnetic resonance imaging is feasible in animal models, but is it feasible in patients?
}

\author{
Amalia Winters, MD, Jessica Forcillo, MD, MSc, and Vinod H. Thourani, MD
}

\footnotetext{
From the Division of Cardiothoracic Surgery, Emory University School of Medicine, Atlanta, Ga.

Disclosures: V.H.T. serves on advisory boards for St Jude Medical, Edwards Lifesciences, and Abbott Medical. V.H.T. performs research for Medtronic, Edwards Lifesciences, St Jude, Directflow, Abbott Medical, and Boston Scientific. All other authors have nothing to disclose with regard to commercial support.

Received for publication Dec 19, 2015; accepted for publication Dec 21, 2015; available ahead of print Jan 30, 2016.

Address for reprints: Vinod H. Thourani, MD, Emory University Hospital Midtown, 550 Peachtree St NE, 6th Floor Medical Office Tower, Atlanta, GA 30308 (E-mail: vthoura@emory.edu).

J Thorac Cardiovasc Surg 2016;151:1413-4

$0022-5223 / \$ 36.00$

Copyright (C) 2016 by The American Association for Thoracic Surgery

http://dx.doi.org/10.1016/j.jtcvs.2015.12.048
}

Imaging remains one of the most critical aspects in the evaluation of a patient in consideration for transcatheter valve procedures. The preoperative assessment of the patient undergoing transcatheter aortic valve replacement (TAVR) includes a combination of computed tomography and transthoracic or transesophageal echocardiography. The use of cardiac-phased computed tomography has led to a significant change in the determination for the size of the prosthesis used, leading to an improvement in paravalvular leaks after TAVR. To date, however, there has been a paucity of advances from the most common intraoperative imaging strategies: fluoroscopy and either transthoracic or transesophageal echocardiography. A noted disadvantage of fluoroscopy potentially includes the high doses of ionizing radiation to which the patient and surgical team are exposed, as well as the relatively poor tissue penetrance in obese patients during the valve replacement procedure. Recently, Horvath and his group have explored magnetic resonance imaging (MRI) as a possible alternative imaging modality during TAVR. ${ }^{1-5}$ This innovative technique may offer superior tissue contrast, nonionizing radiation, and the ability to visualize anatomic landmarks more clearly than with echocardiography. In addition, MRI allows the option to assess myocardial perfusion immediately after the TAVR procedure.

One of the drawbacks of using real-time MRI for TAVR in patients includes the challenge for the medical team of working within the confines of the MRI scanner. ${ }^{1,2}$ Most recently, in their article published in this issue of the Journal, Miller and colleagues ${ }^{3}$ have proposed a novel solution to the technical challenges imposed on a physician operating within the MRI machine by removing the physician from the operative field entirely! To facilitate this, an "MRI compatible robotic surgical assistant system" was designed to position and deliver the aortic valve prosthesis be difficult.

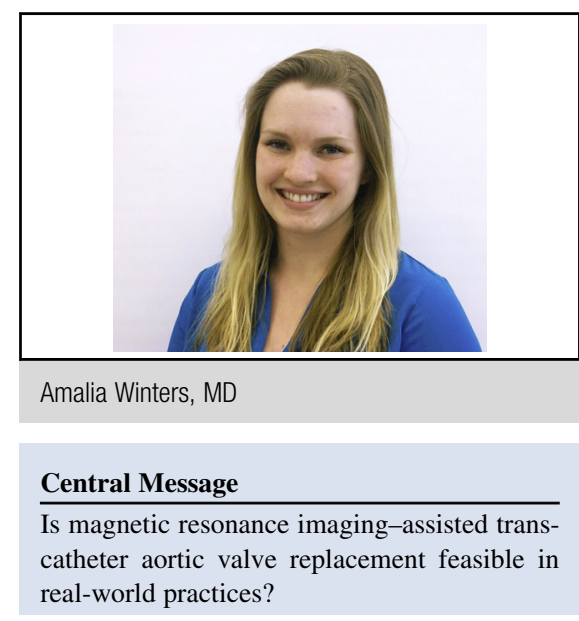

See Article page 1407.

with 1-mm accuracy controlled by custom software. This has the potential for very precise deployment of the TAVR prosthesis, leading to reduced paravalvular leaks. With these techniques, this group has previously done some ground-breaking work by showing excellent longterm survival in a porcine model undergoing intraoperative real time MRI and TAVR. ${ }^{4}$ In this study of Miller and colleagues, ${ }^{3}$ although proper valve placement was confirmed with MRI in all animals after deployment, at necropsy it was noted that the stents were displaced by 1 to $4 \mathrm{~mm}$ relative to the perioperative imaging. Miller and colleagues $^{3}$ mentioned that all 8 stents were implanted $4 \mathrm{~mm}$ below the annulus. In patients with heterogeneous anatomy coupled with a variable root, annular, and subannular calcifications, however, this technique may prove to

Another concern with the robotic assistant system described is that the degree of angulation is stated to be up to 5 degrees of freedom. Although this may be sufficient in routine cases, a surgeon may need more extreme angles to ensure coaxial alignment for optimal valve deployment. In case of an apical catastrophe, does this system allow quick access to the patient?

In an era when it is anticipated that more than $90 \%$ of TAVR procedures will be performed with transfemoral techniques, does this technique lead to a more complex procedure instead of simplification of the 
TAVR procedure, as in the minimalist procedure ${ }^{6}$ Moreover, among the 400 US programs performing TAVR, how many have a hybrid operating room with MRI capability? The relative difficulty of performing intraoperative MRI versus transthoracic echocardiography for a minimalist TAVR procedure or transesophageal echocardiography in an intubated patient is tremendous. The additional cost of a robotic assistant may also be beyond the infrastructure of the majority of TAVR programs.

Miller and colleagues ${ }^{3}$ are to be complimented on their advancements in the development and refinement of the robotic MRI-guided TAVR procedure. Further improvements in this technology with the adoption of transfemoral procedures may truly represent the dawn of a new era.

\section{References}

1. Li M, Mazilu D, Horvath KA. Robotic system for transapical aortic valve replacement with MRI guidance. Med Image Comput Comput Assist Interv. 2008;11(Pt 2):476-84

2. McVeigh ER, Guttman MA, Lederman RJ, Li M, Kocaturk O, Hunt T, et al. Realtime interactive MRI-guided cardiac surgery: aortic valve replacement using a direct apical approach. Magn Reson Med. 2006;56:958-64.

3. Miller JG, Li M, Mazilu D, Hunt T, Horvath KA. Robot-assisted real-time magnetic resonance image guided transcatheter aortic valve replacement. J Thorac Cardiovasc Surg. 2016;151:1407-12.

4. Horvath KA, Mazilu D, Kocaturk O, Li M. Transapical aortic valve replacement under real-time magnetic resonance imaging guidance: experimental results with balloon-expandable and self-expanding stents. Eur J Cardiothorac Surg. 2011;39:822-8.

5. Kindzelski BA, Li M, Mazilu D, Horvath KA. Pathology of balloon-expandable and self-expanding stents following MRI-guided transapical aortic valve replacement. J Heart Valve Dis. 2015;24:139-47.

6. Jensen HA, Condado JF, Devireddy C, Binongo J, Leshnower BG, Babaliaros V, et al. Minimalist transcatheter aortic valve replacement: the new standard for surgeons and cardiologists using transfemoral access? J Thorac Cardiovasc Surg. 2015;150:833-9. 